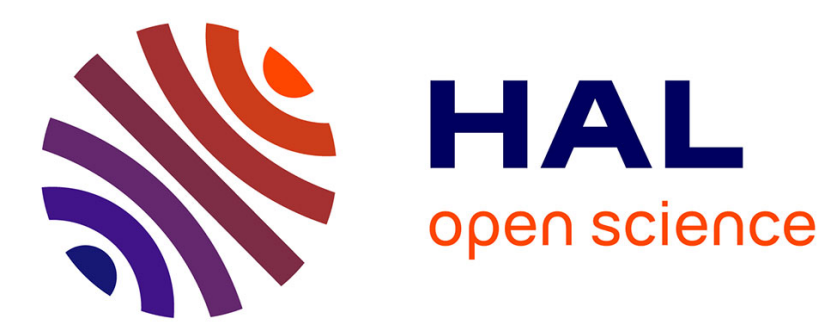

\title{
19. Étude des propriétés électroniques des surfaces de semi-conducteurs par diffusion Raman
}

\author{
P. Corden, A. Pinczuk, E. Burstein
}

\section{To cite this version:}

P. Corden, A. Pinczuk, E. Burstein. 19. Étude des propriétés électroniques des surfaces de semi-conducteurs par diffusion Raman. Revue de Physique Appliquée, 1970, 5 (6), pp.906-906. 10.1051/rphysap:0197000506090601 . jpa-00243489

\section{HAL Id: jpa-00243489 https://hal.science/jpa-00243489}

Submitted on 1 Jan 1970

HAL is a multi-disciplinary open access archive for the deposit and dissemination of scientific research documents, whether they are published or not. The documents may come from teaching and research institutions in France or abroad, or from public or private research centers.
L'archive ouverte pluridisciplinaire HAL, est destinée au dépôt et à la diffusion de documents scientifiques de niveau recherche, publiés ou non, émanant des établissements d'enseignement et de recherche français ou étrangers, des laboratoires publics ou privés. 


\title{
19. ÉTUDE DES PROPRIÉTÉS ÉLECTRONIQUES DES SURFACES DE SEMI-CONDUCTEURS PAR DIFFUSION RAMAN
}

\author{
P. CORDEN, A. PINCZUK et E. BURSTEIN \\ Université de Pennsylvanie, Philadelphie
}

La diffusion Raman peut être utilisée comme un moyen d'étude de la position du niveau de Fermi relatif au bord de bandes près de la surface pour des longueurs d'onde où la profondeur de peau du semi conducteur est petite c'est-à-dire 100-300 $\AA$. Dans $n$-InSb, $p$-InSb, $n$-GaSb, $p$-InAs on observe une raie induite de phonon L0 à la fréquence non absorbée résultant de la présence d'une barrière de Schottky due à la zone de charge d'espace à la surface. Une raie de phonon L0 non absorbée est également observée pour différentes conditions de surface dans InAs dégénéré de type $n$ ce qui permet de supposer qu'il existe une région de charge d'espace au voisinage de la surface. Les résultats sur $n$-InAs sont en contradiction avec les données de la référence [1] qui indiquent que le niveau de Fermi à la surface se trouve à l'intérieur de la bande de conduction.

\section{Bibliographie}

[1] Mead (C. A.), Sitzer (W. G.), Phys. Rev., 1964. 134, A 713 . 